\title{
Retrospective and Current Peer Victimization in College Students with Disabilities: Examining the Intersectionality of Sexual Orientation and Gender
}

\author{
Emily M. Lund ${ }^{1}$ (D) $\cdot$ Scott W. Ross ${ }^{2}$
}

Accepted: 21 November 2020 / Published online: 2 January 2021

(c) The Author(s), under exclusive licence to Springer Science+Business Media, LLC part of Springer Nature 2021

\begin{abstract}
The present, exploratory study examined retrospective and current peer victimization in a multi-university sample of 58 college students with disabilities, 18 (31\%) of whom identified as sexual minorities. Fifty-seven participants reported peer victimization during childhood, and approximately half reported experiencing peer victimization in the past 2 months. Students who identified as sexual minorities reported more retrospective victimization but current victimization did not differ between the two groups. Current and retrospective peer victimization were significantly correlated with present psychological distress. Professionals who work with students with disabilities should be aware of the high prevalence of peer victimization and its psychological correlates in this population.
\end{abstract}

Keywords Peer victimization · Bullying · Psychological distress · Sexual orientation · Social disability $\cdot$ College students $\cdot$ Students with disabilities $\cdot$ United states

\section{Introduction}

Peer victimization is recognized as a serious issue in elementary and secondary schools [1], but little research has examined its prevalence in college and university students. A few existent studies report that approximately $20-25 \%$ of American college students experience peer victimization during college, with some reporting victimization rates of 60-70\% (see Lund and Ross [2] for a review). However, most of the current literature on peer victimization in college students consists of samples drawn from a single university and not examine demographic correlates of peer victimization, thus limiting the generalizability of the results.

Emily M. Lund

emlund@ua.edu; emily.m.lund@gmail.com

1 Department of Educational Studies in Psychology, Research Methodology and Counseling, University of Alabama, PO Box 870231, Tuscaloosa, AL 35487, USA

2 Department of Education and Leadership, California State University at Monterey Bay, Marina, CA 93933, USA 


\section{Peer Victimization in Students with Disabilities}

Recent literature reviews and meta-analyses have found that individuals with disabilities victimization in general [3-5] and peer victimization in particular [6]. Similarly, recent studies of peer victimization in students with disabilities have also found that students with disabilities tend to experience peer victimization at increased or elevated rates compared to the general population $[7,8]$.

It is unclear what exactly puts students with disabilities at increased risk for victimization, and multiple factors may be at play. Rose et al. [6] speculate that students with visible disabilities, such as physical disabilities or sensory loss, may be at increased risk for victimization due to their visible differences from peers. Conversely, students with disabilities that impact social behavior, such as autism, emotional and behavioral disabilities, and attention deficit hyperactivity disorder (ADHD) may be targeted as victims due to socially atypical behavior or difficulties with emotional and behavioral regulation [6, 8]. Additionally, by virtue of their disability status itself, students with disabilities are members of a marginalized group, which may put them at increased risk for peer victimization in and of itself [9]

Although it has been well-established that victimization in general remains an issue for adults with disabilities [3,4], the degree to which peer victimization remains an issue for young adults with disabilities remains an open question. In a study of 339 recent high school graduates and dropouts with disabilities, Doren et al. [10] found that $15 \%$ of the students had reported being bullied in the first year after leaving school. This finding suggests that people with disabilities may continue to be at risk for peer victimization after leaving school but does not provide information on peer victimization in college students specifically. Additionally, the study did not provide information on the relationship between victimization and psychological distress. Similarly, a recent review of the research on the prevalence of peer victimization among college students [2] did not find any studies that collected data on participant disability status or reported the relationship between disability status and bullying victimization or perpetration.

In the only known published study on bullying in college students with disabilities to date, Kowalski et al. [11] surveyed 82 college students with a disability regarding their experiences with traditional (i.e., non-cyber) and cyber bullying perpetration and victimization. They found that $28 \%$ and $13.9 \%$ of the students with disabilities reported being victims of traditional and cyber-bullying, respectively, over the past 2 months, although they did not provide information on the frequency of this victimization or subtypes of non-cyber victimization.

\section{Students with Disabilities Who are Sexual Minorities}

Like students with disabilities, students who are sexual minorities (i.e., are not heterosexual) have been shown to be at increased risk for lifetime victimization [12] as well as peer victimization during secondary school [13]. Although the research on sexual orientation and peer victimization in college students is limited, Wensley and Campbell [14] found that college freshman who identified as non-heterosexual reported more past year peer victimization than did heterosexual participants, suggesting that sexual orientation may continue to be a risk factor for peer victimization in college students. 
Additionally, sexual orientation may interact with disability status and further magnify risk. In a study of over 7000 Oregon high school students, McGee [15] found that sexual minority status and disability status interacted to increase the likelihood of peer victimization. In other words, students who identified as both disabled and being sexual minorities were more likely to experience peer victimization than students with disabilities who identified as heterosexual. It is possible that this increased risk may persist into college.

This interaction between sexual orientation and disability status is an example of the concept of "intersectionality." Intersectionality refers to the cumulative impact of and interaction between multiple aspects of a person's identity, such as race and disability status or race and sexual orientation $[16,17]$. When a person is a member of multiple marginalized groups, the intersectionality of these identities can even further increase their vulnerability towards victimization and difficulty in finding culturally competent services and support that can appropriately and competently address multiple aspects of a student's identity.

\section{Peer Victimization and Psychological Distress}

Both longitudinal [18] and retrospective $[19,20]$ research indicates that peer victimization may have long-term impacts on physical, psychological, and social well-being. Meta-analyses with children and adolescents have linked peer victimization with depression and anxiety [21] as well as heightened risk for suicidal thoughts and behaviors [22]. As with younger students, preliminary research indicates that peer victimization in college students may be linked with poorer psychological health outcomes, including depression and suicidal thoughts and behaviors [23].

\section{Purpose}

The purpose of the present study was to examine the rates of retrospective and current peer victimization in a multi-university sample of college students with disabilities in the United States, including investigating the basic psychometrics of victimization measures in this population. Additionally, this exploratory study examined the potential intersecting impact of demographic factors such as age, gender, and sexual orientation on peer victimization. Finally, we examined the relationship between current and retrospective peer victimization and psychological distress. To that end, the research questions are as follows:

(1) What is the internal consistency of measures of current and retrospective victimization and psychological distress in a sample of college students with disabilities?

(2) What are the rates of self-reported retrospective and current peer victimization in a multi-university sample of college students with disabilities?

(3) Do the rates of retrospective and current victimization differ for college students with disabilities based on sexual minority status or gender?

(4) How do retrospective and current peer victimization relate to current levels of psychological distress? 


\section{Method}

\section{Recruitment}

This study was based on online self-report measures filled out by participants via a secure online server connected to a university. The survey was checked for Section 508 compliance (i.e., screen reader accessibility), and the study materials and recruitment methods were approved by the university institutional review broad (IRB) prior to data collection. All participants indicated their consent to participate in the study prior to beginning the survey and could opt out at any time without penalty. Responses were never linked to identifying information. Data collection took place in March and April 2014. Participants took approximately 5-15 min to complete the survey; high reliability on the measures used, as discussed in the "Results" section, indicates consistent and non-random responding.

In order to recruit an adequate sample of participants with disabilities, participants were recruited in two waves. The first wave of participants $(n=29)$ were recruited as part of a larger study on peer victimization and psychological health in American college students $(n=485)$. In order to be included in the present analysis, participants had to (a) answer "yes" to the disability item and (b) have complete data on at least one victimization measure. Participants in this study were recruited from American users of Amazon Mechanical Turk (MTurk), an online survey recruitment system in which participants are paid small sums to complete surveys and other tasks. Researchers have found that MTurk samples yield valid and reliable data [24-27]. These participants were paid \$0.50 through MTurk for their participation.

In order to increase the number of participants with disabilities, we conducted a second wave of recruitment that specifically targeted college students with disabilities. Specifically, we sent out recruitment emails through the Disabled Student Services in Higher Education (DSSHE) listserv as well as some disability studies-related academic listservs; we asked listserv members to please send out the recruitment email to their students. DSSHE was our primary target, as its membership consists of a large number of professionals who work in disability services offices at colleges and universities around the United States. Although we do not know the exact number of offices represented on the listserv, informal observation of the listserv activity over several years suggests a relative large and active group of participants who represent a wide variety of colleges and universities across the United States. Because we did not ask listserv members to report back on whether or not they did so, we cannot be sure of how many offices did so. Due to university regulations regarding participant compensation, we were unfortunately unable to compensate participants recruited in this second wave, which may have limited our response rate during this second wave of recruitment. This wave of recruitment also resulted in $n=29$ usable responses; responses were considered usable if participants answered the disability and sexual orientation demographic questions and completed all of the items on at least one of the two victimization questionnaires.

Because of the use of two different waves of data collection from different sources, we examined the two groups (i.e., the listserv and MTurk samples) for equivalence or lack thereof on demographic and study variables. The listserv sample was significantly younger $[t(56)=2.25, p=0.028]$, more heavily female $\left[\chi^{2}(1)=10.99, p=0.001\right]$, and more likely to be heterosexual $\left[\chi^{2}(1)=8.06, p=0.005\right]$. MTurk has been shown to be more balanced in terms of gender than other online recruitment methods [27] and to sample a relatively high proportion of non-heterosexual participants [28], which may explain these demographic 
differences. However, the two groups did not differ significantly on any outcome measure (i.e., current peer victimization, retrospective peer victimization, or psychological distress) and thus were combined for analyses.

\section{Participants}

The total sample $(n=58)$ was $65.5 \%$ female and had a mean age of 25.38 years old $(S D=7.37$, range $=18-49$ years old). We included an "other" option (with an additional option to write in text) for gender for participants who identified outside the gender binary; however, no participants in the present sample selected this option. About a third of the sample were college sophomores, a quarter were seniors, and a fifth were juniors. Ten percent were freshmen, and $8.6 \%$ were graduate students. Two students selected "other"-one indicated that they were a certificate student, and the other indicated that they were in their seventh year of study.

The sample was $84.8 \%$ White, with $75.9 \%$ selecting White or Caucasian as their sole racial or ethnic identity and $8.6 \%$ indicating that they identified with multiple racial or ethnic groups. A complete breakdown of racial and ethnic data can be seen in Table 1.

Just under a third of the sample (31\%) identified as non-heterosexual. About $7 \%$ identified as gay or lesbian, $15.5 \%$ as bisexual, $2 \%$ as asexual, and $5.2 \%$ as not sure or questioning.

In terms of type of disability, most common types of disabilities reported were psychiatric disabilities (43.1\%), ADHD (24.1\%), and chronic health conditions (20.7\%). A third of participants (36.2\%) indicated that they had multiple disabilities. Of these, one had four disabilities, one had three, and the remaining 19 had two. Complete demographic information, including disability type, is in Table 1.

\section{Measures}

\section{Demographics}

Demographic items assessed participants' age, gender, race/ethnicity, sexual orientation, and disability status as well as characteristics about their post-secondary education (i.e., size of college or university, major, GPA, and fraternity/sorority affiliation).

\section{Psychological Distress}

Psychological distress was assessed using the 10 item Kessler Distress Scale (KDS [29]), which asked participants how often they have experienced 10 symptoms of psychological distress over the past four weeks. Items are rated on five a point Likert-type scale from 1-"all of the time" to 5-"none of the time", with higher scores representing lower psychological distress. It has demonstrated good specificity and sensitivity and excellent internal consistency $(\alpha=0.93)$ in previous studies [29].

\section{Current Peer Victimization}

Current peer victimization was assessed using the six victimization items from the Pacific Rim Bullying questionnaire (PRB; [30]). The PRB assesses the frequency of cyber, 
Table 1 Sample characteristics

\begin{tabular}{|c|c|c|c|}
\hline Characteristic & MTurk $(n=29)$ & Listserv $(n=29)$ & Total $(n=58)$ \\
\hline Age (mean, SD) & $27.48(8.07)$ & $23.28(6.02)$ & $25.38(7.37)$ \\
\hline GPA (mean, SD) $(n=54)$ & $3.43(.38)$ & $3.32(.57)$ & $3.37(.480)$ \\
\hline \multicolumn{4}{|l|}{ Gender } \\
\hline Male & $55.2 \%(16)$ & $13.8 \%(4)$ & $34.5 \%(20)$ \\
\hline Female & $44.8 \%(13)$ & $86.2 \%(25)$ & $65.5 \%(38)$ \\
\hline \multicolumn{4}{|l|}{ Race/ethnicity } \\
\hline African-American/Black & $6.9 \%(2)$ & - & $3.4 \%(2)$ \\
\hline Arab/Middle Eastern & - & $3.4 \%(1)$ & $1.7 \%(1)$ \\
\hline Asian/Pacific Islander & $10.3 \%(3)$ & $3.4 \%(1)$ & $6.9 \%(4)$ \\
\hline Caucasian/White & $82.8 \%(24)$ & $82.8 \%(24)$ & $82.8 \%(48)$ \\
\hline Hispanic/Latino/a & $6.9 \%(2)$ & $13.8 \%(4)$ & $10.3 \%(6)$ \\
\hline Native American/Alaskan Native & $3.4 \%(1)$ & - & $1.7 \%(1)$ \\
\hline Do not wish to say & $3.4 \%(1)$ & - & $1.7 \%(1)$ \\
\hline \multicolumn{4}{|l|}{ Sexual orientation } \\
\hline Heterosexual & $51.7 \%(15)$ & $86.2 \%(25)$ & $69 \%(40)$ \\
\hline Gay/lesbian & $10.3 \%(3)$ & $3.4 \%(1)$ & $6.9 \%(4)$ \\
\hline Bisexual & $27.6 \%(8)$ & $3.4 \%(1)$ & $15.5 \%(9)$ \\
\hline Asexual & $3.4 \%(1)$ & $3.4 \%(1)$ & $3.4 \%(2)$ \\
\hline Not sure/questioning & $6.9 \%(2)$ & $3.4 \%(1)$ & $5.2 \%(3)$ \\
\hline \multicolumn{4}{|l|}{ Disability } \\
\hline Physical/orthopedic disability & $3.4 \%(1)$ & $24.1 \%(7)$ & $13.8 \%(8)$ \\
\hline Chronic health condition & $20.7 \%(6)$ & $20.7 \%(6)$ & $20.7 \%(12)$ \\
\hline Deaf/HOH or hearing impaired & $3.4 \%(1)$ & - & $1.7 \%(1)$ \\
\hline Blind/visually impaired & $6.9 \%(2)$ & $17.2 \%(5)$ & $12.1 \%(7)$ \\
\hline Cognitive disability/TBI & - & $3.4 \%(1)$ & $1.7 \%(1)$ \\
\hline Learning disability & $13.8 \%(4)$ & $10.3 \%(3)$ & $12.1 \%(7)$ \\
\hline ADHD & $17.2 \%(5)$ & $31.0 \%(9)$ & $24.1 \%(14)$ \\
\hline Autism spectrum disorder & $13.8 \%(4)$ & $10.3 \%(3)$ & $12.1 \%(7)$ \\
\hline Psychiatric disability & $44.8 \%(13)$ & $41.4 \%(12)$ & $43.1 \%(25)$ \\
\hline \multicolumn{4}{|l|}{ Size of college or university } \\
\hline Less than 2000 students & $3.4 \%(1)$ & $3.4 \%(1)$ & $3.4 \%(2)$ \\
\hline 2000-5000 students & $34.5 \%(10)$ & $20.7 \%(6)$ & $27.6 \%(16)$ \\
\hline $5000-10,000$ students & $10.3 \%(3)$ & $24.1 \%(7)$ & $17.3 \%(10)$ \\
\hline $10,000-20,000$ students & $31.0 \%(9)$ & $6.9 \%(2)$ & $19.0 \%(11)$ \\
\hline More than 20,000 students & $20.7 \%(6)$ & $44.8 \%(13)$ & $32.8 \%(19)$ \\
\hline \multicolumn{4}{|l|}{ Type of college } \\
\hline 2 year & $27.6 \%(8)$ & - & $13.6 \%(8)$ \\
\hline 4 year & $72.4 \%(21)$ & $100 \%(29)$ & $86.4 \%(50)$ \\
\hline \multicolumn{4}{|l|}{ Year in college } \\
\hline Freshman & $2(6.9 \%)$ & $13.8 \%(4)$ & $10.3 \%(6)$ \\
\hline Sophomore & $41.4 \%(12)$ & $24.1 \%(7)$ & $32.8 \%(19)$ \\
\hline Junior & $20.7 \%(6)$ & $20.7 \%(6)$ & $20.7 \%(12)$ \\
\hline Senior & $27.6 \%(8)$ & $20.7 \%(6)$ & $24.1 \%(14)$ \\
\hline Graduate student & $3.4 \%(1)$ & $13.8 \%(4)$ & $8.6 \%(5)$ \\
\hline
\end{tabular}


Table 1 (continued)

\begin{tabular}{|c|c|c|c|}
\hline Characteristic & MTurk $(n=29)$ & Listserv $(n=29)$ & Total $(n=58)$ \\
\hline Other & - & $6.9 \%(2)$ & $3.4 \%(2)$ \\
\hline \multicolumn{4}{|c|}{ Affiliation with a social fraternity or sorority } \\
\hline Current & - & $6.9 \%(2)$ & $3.4 \%(2)$ \\
\hline Previous & - & $6.9 \%(2)$ & $3.4 \%(2)$ \\
\hline None & $100 \%(29)$ & $86.2 \%(25)$ & $93.1 \%(54)$ \\
\hline
\end{tabular}

GPA grade point average, $\mathrm{HOH}$ hard of hearing; $T B I$ traumatic brain injury

physical, verbal, and relational aggression as well as property damage, theft, and joking physical aggression over the past 2 months. When selecting peer victimization measures, we looked for measures that did not use potentially loaded or confusing terminology like "bullying," "bully," "perpetrator," and "victim." Instead, we selected measures where items specifically asked about whether or not a participant had been the target of specific peer behaviors, such as having rumors spread about them, leaving someone out, hitting, kicking, or insulting someone. The focus on behavior instead of terminology is potentially advantageous, as research has suggested that the use of the term "bullying" may cause students to underreport victimization due to confusion or concern about whether or not a given behavior meets the threshold of "bullying" [31, 32].

The PRB has demonstrated good reliability and factor structure in diverse samples [30]. Total victimization scores can be calculated by summing together the scores for all six items; because there is some controversy over whether or not "joking" physical aggression should be counted as peer victimization, scores were calculated both with and without that item, as has been done in previous research using the PRB [33].

\section{Retrospective Peer Victimization}

Retrospective peer victimization was assessed using the Retrospective Bullying Questionnaire (RBQ) [19]. The RBQ consists of 12 items that ask participants how often they experienced certain peer victimization behaviors during childhood and begins with prompting question, "During your childhood, how often did other kids do this to you in a deliberately hurtful way?" The items on the RBQ cover physical, verbal, relational, and exclusionary aggression during childhood; the specific items are listed in Table 3. Each item is scored on a five point scale, with "never" and "most of the time" used as anchors. Initial use of the measure in a sample of 582 university students in the United Kingdom demonstrated good test-retest reliability (0.84) [19]. Like the PRB, the RBQ avoids the use of the bullying terminology, lending consistency to the two measures.

\section{Analyses}

For research question one, we used Cronbach's alpha to assess internal consistency. For research question two, we used simple descriptive statistics to describe the prevalence of different types of retrospective and current peer victimization. For research question three, we used paired sample t-tests to compare means across groups and also calculated Cohen's $d$ effect sizes; per Cohen [34], we used effect sizes of 0.2, 0.5, and 0.8 as benchmarks 
for small, medium, and large differences, respectively. For research question four, we used Person's correlation to assess the relationships between the RBQ, PRB, and KDS. Except where otherwise specified, six-item PRB scores were used in analyses.

\section{Results}

\section{Internal Consistency of Measures}

All measures demonstrated acceptable to excellent reliability in the present sample. The means, standard deviations, and internal consistency (Cronbach's alpha) for each measure can be seen in Table 2. According to standard guidelines [35], the PRB demonstrated acceptable or better internal consistency in this sample, the KDS demonstrated very good internal consistency, and the RBQ demonstrated excellent internal consistency. These results suggest that the total score on each measure represents a single construct and thus can be safely used in analyses.

\section{Prevalence and Types of Victimization}

\section{Retrospective Victimization}

All but one participant (98.3\%) reported experiencing peer victimization during their childhood. The most common types of retrospective peer victimization reported were verbal victimization (93.1\%) and social exclusion (91.4\%). Relational (74.1\%) and physical $(69.0 \%)$ victimization were less commonly endorsed but still frequent. Means were higher for the frequency of verbal victimization $(M=10.10)$ and social exclusion $(M=9.72)$ than physical $(M=5.50)$ and relational $(M=7.24)$ victimization The percent of participants endorsing each item individual item and the mean frequencies can be seen in Table 3.

\section{Current Victimization}

When all six items on the PRB were included, slightly over half of participants (53.4\%) reported experiencing some type of victimization within the past 2 months. When joking physical aggression was excluded, just under half of participants $(47.4 \%)$ reported experiencing victimization over the past 2 months. The most common types of current victimization reported were relational (42.6\%), verbal (33.7\%), and cyber $(22.4 \%)$ victimization. Relational and verbal aggression were also the most common types of peer victimization

Table 2 Means and internal consistency of measures

\begin{tabular}{lllll}
\hline Measure & Possible range & $\mathrm{N}$ & Mean (SD) & Alpha \\
\hline KDS & $10-50$ & 56 & $34.93(8.32)$ & .897 \\
RBQ & $12-60$ & 58 & $32.57(11.31)$ & .912 \\
PRB & $0-18$ & 56 & $2.11(3.07)$ & .825 \\
PRB (excluding joking & $0-15$ & 57 & $1.72(2.44)$ & .773 \\
physical aggression) & & & & \\
\hline
\end{tabular}

$K D S$ Kessler Distress Scale (10 item), $R B Q$ Retrospective Bullying Questionnaire; $P R B$ Pacific Rim Bullying measure 
Table 3 Retrospective childhood peer victimization $(n=58)$

\begin{tabular}{lll}
\hline Type of retrospective victimization & $\begin{array}{l}\text { Percent } \\
\text { reporting } \\
\text { any }\end{array}$ & Mean (SD) \\
& & \\
\hline Physical & $48.3 \%$ & $1.79(1.02)$ \\
Hit & $32.8 \%$ & $1.60(1.06)$ \\
Kicked & $65.5 \%$ & $2.10(1.05)$ \\
Pushed & $69.0 \%$ & $5.50(2.77)$ \\
Any physical & & \\
Verbal & $87.9 \%$ & $3.55(1.40)$ \\
Teased in a mean way & $82.8 \%$ & $3.41(1.36)$ \\
Called nasty names & $91.4 \%$ & $3.14(1.44)$ \\
Verbally insulted & $93.1 \%$ & $10.10(4.02)$ \\
Any verbal & & \\
Exclusion & $81.0 \%$ & $3.10(1.50)$ \\
Left out on purpose & $84.5 \%$ & $3.38(1.45)$ \\
Not asked to join in & $87.9 \%$ & $3.24(1.34)$ \\
Ignored & $91.4 \%$ & $9.72(3.93)$ \\
Any exclusion & & \\
Relational & $67.2 \%$ & $2.60(1.44)$ \\
Damaged their friendships & $62.1 \%$ & $2.45(1.39)$ \\
Tried to make other people dislike them & $2.19(1.28)$ \\
Spoilt their relationships & $74.1 \%$ & $7.24(3.64)$ \\
Any relational & $98.3 \%$ & \\
\hline & & \\
\hline & & \\
\hline
\end{tabular}

${ }^{1}$ Response options for individual items range from 1 ("never") to 5 ("most of the time). Accordingly, totals for each subtype of victimization range from 3 to 15

reported, with $15.5 \%$ experiencing relational aggression at least once a week and $12.2 \%$ experiencing verbal aggression at least once a week. Conversely, only $6.9 \%$ of participants reported experiencing property damage or theft over the past months and only $10.3 \%$ reported experiencing intentional physical aggression. More participants (18.5\%) reported experiencing joking physical aggression. Moreover, 10.5\% reported experiencing joking physical aggression at least once a week or more. Breakdowns of participant responses for each type of victimization can be seen in Table 4.

\section{Differences in Victimization by Sexual Orientation and Gender}

\section{Retrospective Victimization}

Retrospective victimization scores did not differ by gender $[t(56)=.641 ; p=0.524$, $d=0.17]$ or age $(r=0.080 ; p=0.549)$. However, non-heterosexual students $(M=37.39$, $S D=9.73)$ reported significantly more retrospective victimization $[t(56)=2.254, p=0.028$, $d=0.66]$ than their heterosexual counterparts $(M=30.40, S D=11.40)$.

Compared to heterosexual students, student who are sexual minorities reported more significantly more retrospective verbal victimization $[t(56)=2.041, p=0.046, d=0.61]$. The two 
Table 4 Current (past 2 months) victimization $(n=58)$

\begin{tabular}{lcccc}
\hline Type of victimization & Never & Once or twice & Once a week & $\begin{array}{c}\text { Several } \\
\text { times a } \\
\text { week }\end{array}$ \\
\hline Physical (joking) $^{\mathrm{a}}$ & $82.5 \%$ & $7.0 \%$ & $3.5 \%$ & $7.0 \%$ \\
Physical (on purpose) & $89.7 \%$ & $1.7 \%$ & $1.7 \%$ & $6.9 \%$ \\
Property $^{\mathrm{a}}$ & $93.1 \%$ & $3.4 \%$ & $1.7 \%$ & $1.7 \%$ \\
Verbal $^{\mathrm{a}}$ & $66.7 \%$ & $21.1 \%$ & $7.0 \%$ & $5.3 \%$ \\
Relational & $58.6 \%$ & $25.9 \%$ & $12.1 \%$ & $3.4 \%$ \\
Cyber & $77.6 \%$ & $17.2 \%$ & $3.4 \%$ & $1.7 \%$ \\
\hline
\end{tabular}

${ }^{\mathrm{a}} n=57$

groups did not differ significantly in retrospective physical peer victimization $[t(56)=1.446$, $p=0.154, d=0.42]$, relational peer victimization $[t(56)=1.550, p=0.127, d=0.43]$, or peer rejection $[t(56)=1.839, p=0.071, d=0.53]$. However, the difference for peer rejection was nearing significance and the effect size was moderate [34].

\section{Current Victimization}

Current victimization did not differ significantly by age $(r=-0.155 ; p=0.255)$ or sexual orientation $[t(39.93)=.389 ; p=0.700, d=-0.11]$. However, women $(M=2.65, S D=3.50)$ reported significantly more victimization $[t(53.6)=2.33, p=0.023, d=0.59]$ than men $(M=1.05, S D=1.61)$. Students who are sexual minorities did not significantly differ from those who are not on any individual type of current victimization.

\section{Relationship Between Current and Retrospective Peer Victimization}

Current victimization was not significantly associated with retrospective victimization when all six items on the PRB were included $(r=0.250, p=0.063)$. However, current victimization was significantly correlated with retrospective victimization when joking physical aggression was excluded from the PRB $(n=57 ; r=0.294 p=0.026)$. This provides tentative support for the notion that students who experience more peer victimization as children may be more vulnerable to victimization as young adults.

\section{Victimization and Psychological Distress}

Greater psychological distress was significantly correlated with high levels of current victimization ( $n=54 ; r=-0.318 ; p=0.019$ ). Additionally, higher levels of retrospective victimization were also significantly correlated with greater psychological distress $(n=56 ; r=-0.268$, $p=0.046)$. Students who identified as sexual minorities $(M=32.88, S D=8.74)$ did not report significantly different levels of current psychological distress than those who identified as heterosexual $[M=35.82, S D=8.08 ; t(54)=1.22, p=0.227, d=0.35]$. 


\section{Discussion}

This article reports the results of an exploratory study of current and retrospective peer victimization in college students with disabilities. In addition to reporting victimization rates for the entire sample, the relationship between sexual orientation and victimization was also examined.

Retrospective (childhood) peer victimization was almost universally reported by participants, and peer victimization in the past 2 months was reported by almost half of participants. The rate of college victimization reported in this study is higher than many, although not all, studies of peer victimization in the college population [2] and slightly higher than the combined rates of cyber- and traditional victimization reported by college students with disabilities in Kowalski and colleagues' study [11]. Given the variance in victimization rates among college students in general [2] and the lack of data on victimization in college students with disabilities specifically, it is yet unclear how the rates of peer victimization in our sample might compare to larger samples of college students with disabilities and if and how recent phenomena like the ongoing 2019 novel coronavirus (COVID-19) pandemic might change these rates in new samples.

With regards to the intersection of sexual orientation and disability, things do actually appear to "get better" for sexual minority students with disabilities after they transition to college. Although these students reported greater victimization during childhood, their current levels of victimization in college were roughly equal to those reported by their heterosexual peers. However, given that retrospective victimization was still related to current psychological distress in our sample, college counselors, mental health counselors, rehabilitation counselors, and others who work with students with disabilities and sexual minority students should still be mindful of the potential effects of pre-college student victimization on student mental health.

Women with disabilities did not report greater retrospective victimization than their male counterparts, yet they did report significantly more current victimization. This seems to suggest that the college environment may pose greater risks for victimization to female students with disabilities than pre-college educational environments. This may be parallel to the generally high risk for interpersonal violence, such as sexual assault, among female college students [36] and may point to an overall higher degree of vulnerability to victimization in female college students, including non-sexual victimization.

Finally, retrospective and current victimization were significantly related, suggesting that previous victimization may be related to an increased risk of current victimization. This is similar to the findings of Blake and colleagues [37] who found that peer victimization in elementary school students with disabilities tended to be chronic and stable across time. Interestingly, students who were sexual minorities did not report significantly greater psychological distress compared to their heterosexual peers.

\section{Implications for Practitioners}

Practitioners who work with people with disabilities are tasked with advocating against discrimination and other prejudiced and unfair treatment of individuals with disabilities and with educating themselves regarding social issues that affect people with disabilities [38]. This may include being aware of the extent of peer victimization and its effects in young adults with disabilities, especially as bullying is increasingly being recognized as a 
major social and public health issue. By better understanding the prevalence, nature, and sequalae of peer victimization among their clients, professionals who work with college students with disabilities may be better prepared to collaborate with providers and agencies to respond to the social and psychological experiences and needs of their clients. Such person-centered collaboration may increase the support and engagement of clients and thus facilitate better outcomes [39].

These results suggest that peer victimization is a major issue for students with disabilities, both before and during college. Professionals who work with students with disabilities who are or will be attending college should be aware that the high prevalence of peer victimization among students with disabilities does not end when they enter college. Similarly, they should be aware of the potential negative impact of that victimization on psychological well-being and the increased risk of victimization, particularly verbal victimization, in students with disabilities who are also sexual minorities. Working with clients on strategies to cope with and minimize the negative effects of current and former peer victimization may be helpful.

\section{Limitations and Future Research}

The present study is limited by its relatively small sample size $(n=58)$, which limits both the generalizability of the results and our ability to assess the impact of different demographic variables on victimization rates. Future researchers should replicate this study with a larger sample in order to confirm the results and to further assess the impact of demographic variables such as race and ethnicity on peer victimization in college students with disabilities. In future studies, researchers who use listserv recruitment to contact disability services offices should ask listserv members to indicate if they send the survey to their students. This would allow the researchers to collect and report more precise information on the number of participating institutions. Collection of a large sample from a single recruitment source would also help address demographic differences that occur when combining multiple samples, as with the present study.

Additionally, this study is limited by the lack of data on when participants acquired their disability or disabilities. Some participants likely acquired their disability after childhood or adolescence, meaning that the experience of disability did not factor into their likelihood of peer victimization during childhood. Future studies could address these issues with a longitudinal design that followed students with disabilities from elementary or secondary school into college, collecting data on victimization at multiple points in time. Alternatively, researchers could ask participants when they acquired a disability and control for this when examining retrospective victimization data. Questions about when participants acquired their disability were left out of the current study due to the broader nature of the first wave of data collection, but researchers who conduct future studies on this topic should be sure to collect this type of data.

This study is also limited by the lack of responses from transgender and non-binary participants; although we included an option for participants outside the gender binary to identify themselves, no participants in the present study chose that option. Although MTurk has been shown to be a good recruitment method for sexual minority participants, few non-cisgender participants are included in general MTurk samples [28]. Thus, specifically targeted recruitment methods may be needed to recruit transgender and non-binary college students, including transgender and non-binary students with disabilities, in order to capture their lived experiences of peer victimization. 
Researchers should examine comparative rates of peer victimization and perpetration for college students with and without disabilities. This would allow for a direct comparison of victimization and perpetration rates between college students with and without disabilities using a unified methodology. Studies on peer victimization and perpetration in high school students with disabilities have shown elevated rates of both perpetration and victimization [6], and Kowalski et al. [11] found that college students with disabilities were more likely than those without disabilities to engage in cyber-bullying but not traditional bullying. Collecting further data on both perpetration and victimization could allow researchers to see if these trends are seen in other samples of college students with disabilities. Researchers are starting to examine the validity of the PRB and RBQ in general adult samples; this could help guide future studies in this area by instilling greater confidence in and understanding of these measures in adults, both in and outside of the college context.

Finally, researchers may wish to examine the relationship between retrospective and current victimization and other mental health variables, such as suicidality and non-suicidal self-injury. Such behaviors cause significant concerns for college and university staff in terms of both student well-being and legal liability [40], and peer victimization has been consistently linked to suicidality in pre-college student populations [22]. Additionally, researchers have found that people with disabilities report increased suicidality even when depressive symptoms are controlled for in statistical analyses [25], making them a particularly important population with regards to suicide prevention efforts. Thus, it may be useful to examine the relationship between peer victimization and suicidality in college students with disabilities.

\section{Conclusion}

Peer victimization appears to be a consistent issue for students with disabilities, with approximately half of participants reporting peer victimization in the past 2 months and almost all reporting victimization during childhood. Students who were also sexual minorities reported significantly greater retrospective peer victimization but similar levels of current peer victimization, suggesting that things do perhaps "get [relatively] better" in postsecondary education for students with disabilities who are sexual minorities. The current study suggests that students with disabilities continue to experience psychological distress as a result of past and current victimization, although sexual minority students with disabilities did not report significantly greater current psychological distress. These findings should be given careful consideration by rehabilitation counselors, disability services personnel, and others who work with students with disabilities.

\section{References}

1. Wang, J., Iannotti, R.J., Nansel, T.R.: School bullying among adolescents in the United States: physical, verbal, relational, and cyber. J. Adolesc. Health 45(4), 368-375 (2009). https://doi.org/10.1016/j. jadohealth.2009.03.021

2. Lund, E.M., Ross, S.W.: Bullying perpetration, victimization, and demographic differences in college students: a review of the literature. Trauma Violence Abuse 18(3), 348-360 (2017). https://doi. org/10.1177/1524838015620818

3. Hughes, K., Bellis, M.A., Jones, L., et al.: Prevalence and risk of violence against adults with disabilities: a systematic review and meta-analysis of observational studies. Lancet 379(9826), 1621-1629 (2012). https://doi.org/10.1016/s0140-6736(11)61851-5 
4. Hughes, R.B., Lund, E.M., Gabrielli, J., Powers, L.E., Curry, M.A.: Prevalence of interpersonal violence against community-living adults with disabilities: a literature review. Rehabil. Psychol. 56(4), 302-319 (2011). https://doi.org/10.1037/a0025620

5. Jones, L., Bellis, M.A., Wood, S., et al.: Prevalence and risk of violence against children with disabilities: a systematic review and meta-analysis of observational studies. Lancet 380(9845), 899-907 (2012). https://doi.org/10.1016/s0140-6736(12)60692-8

6. Rose, C.A., Monda-Amaya, L.E., Espelage, D.L.: Bullying perpetration and victimization in special education: a review of the literature. Remedial Spec. Educ. 32(2), 114-130 (2011). https://doi. org/10.1177/0741932510361247

7. Rose, C.A., Espelage, D.L., Monda-Amaya, L.E.: Bullying and victimisation rates among students in general and special education: a comparative analysis. Educ. Psychol. 29(7), 761-776 (2009). https:// doi.org/10.1080/01443410903254864

8. Blake, J.J., Lund, E.M., Zhou, Q., Kwok, O.-M., Benz, M.R.: National prevalence rates of bully victimization among students with disabilities in the United States. Sch. Psychol. Q. 27(4), 210-222 (2012). https://doi.org/10.1037/spq0000008

9. Lund, E.M., Blake, J.J., Ewing, H.K., Banks, C.S.: School counselors' and school psychologists' bullying prevention and intervention strategies: A look into real-world practices. J. Sch. Violence 11(3), 246-265 (2012). https://doi.org/10.1080/15388220.2012.682005

10. Doren, B., Bullis, M., Benz, M.R.: Predictors of victimization experiences of adolescents with disabilities in transition. Except. Child. 63(1), 7-18 (1996). https://doi.org/10.1177/001440299606300101

11. Kowalski, R.M., Morgan, C.A., Drake-Lavelle, K., Allison, B.: Cyberbullying among college students with disabilities. Comput. Hum. Behav. 57, 416-427 (2016). https://doi.org/10.1016/j.chb.2015.12.044

12. Katz-Wise, S.L., Hyde, J.S.: Victimization experiences of lesbian, gay, and bisexual individuals: a meta-analysis. J. Sex Res. 49(2-3), 142-167 (2012). https://doi.org/10.1080/00224499.2011.637247

13. Friedman, M.S., Marshal, M.P., Guadamuz, T.E., et al.: A meta-analysis of disparities in childhood sexual abuse, parental physical abuse, and peer victimization among sexual minority and sexual nonminority individuals. Am. J. Public Health 101(8), 1481-1494 (2011). https://doi.org/10.2105/ ajph.2009.190009

14. Wensley, K., Campbell, M.: Heterosexual and nonheterosexual young university students' involvement in traditional and cyber forms of bullying. Cyberpsychology Behav. Soc. Netw. 15(12), 649-654 (2012). https://doi.org/10.1089/cyber.2012.0132

15. Mcgee, M.G.: Lost in the margins? intersections between disability and other nondominant statuses with regard to peer victimization. J. Sch. Violence 13(4), 396-421 (2014). https://doi. org/10.1080/15388220.2014.894914

16. Lightfoot, E., Williams, O.: The intersection of disability, diversity, and domestic violence: results of national focus groups. J. Aggress. Maltreatment Trauma 18(2), 133-152 (2009). https://doi. org/10.1080/10926770802675551

17. Crenshaw, K.: Demarginalizing the intersection of race and sex: a black feminist critique of antidiscrimination doctrine, feminist theory and antiracist politics. Univ. Chic. Legal Forum, 139 (1989).

18. Wolke, D., Copeland, W.E., Angold, A., Costello, E.J.: Impact of bullying in childhood on adult health, wealth, crime, and social outcomes. Psychol. Sci. 24(10), 1958-1970 (2013). https://doi. org/10.1177/0956797613481608

19. Boulton, M.J.: Associations between adults' recalled childhood bullying victimization, current social anxiety, coping, and self-blame: evidence for moderation and indirect effects. Anxiety Stress Coping 26(3), 270-292 (2013). https://doi.org/10.1080/10615806.2012.662499

20. Zou, C., Andersen, J.P., Blosnich, J.R.: The association between bullying and physical health among gay, lesbian, and bisexual individuals. J. Am. Psychiatr. Nurses Assoc. 19(6), 356-365 (2013). https:// doi.org/10.1177/1078390313510739

21. Hawker, D.S.J., Boulton, M.J.: Twenty years' research on peer victimization and psychosocial maladjustment: a meta-analytic review of cross-sectional studies. J. Child Psychol. Psychiatry 41(4), 441455 (2000). https://doi.org/10.1111/1469-7610.00629

22. Klomek, A.B., Sourander, A., Gould, M.: The association of suicide and bullying in childhood to young adulthood: a review of cross-sectional and longitudinal research findings. Can. J. Psychiatry. 55(5), 282-288 (2012). https://doi.org/10.1177/070674371005500503

23. Schenk, A.M., Fremouw, W.J.: Prevalence, psychological impact, and coping of cyberbully victims among college students. J. Sch. Violence. 11(1), 21-37 (2012). https://doi.org/10.1080/15388 220.2011.630310

24. Buhrmester, M., Kwang, T., Gosling, S.D.: Amazon's Mechanical Turk: A new source of inexpensive, yet high-quality data? Perspect. Psychol. Sci. 6(1), 3-5 (2011). https://doi.org/10.1177/1745691610 393980 
25. Lund, E.M., Nadorff, M.R., Seader, K.: Relationship between suicidality and disability when accounting for depressive symptomology. Rehabil. Couns. Bull. 59(3), 185-188 (2016). https://doi. org/10.1177/0034355215586388

26. Mason, W., Suri, S.: Conducting behavioral research on Amazon's Mechanical Turk. Behav. Res. Methods 44(1), 1-23 (2011). https://doi.org/10.3758/s13428-011-0124-6

27. Thomas, K.B., Lund, E.M., Bradley, A.R.: Composite trauma and mental health diagnosis as predictors of lifetime nonsuicidal self-injury history in an adult online sample. J. Aggress. Maltreatment Trauma 24(6), 623-635 (2015). https://doi.org/10.1080/10926771.2015.1049766

28. Lund, E.M., Thomas, K.B., Sias, C.M., Bradley, A.R.: Examining concordant and discordant sexual and romantic attraction in American adults: implications for counselors. J. LGBT Issues Couns. 10(4), 211-226 (2016). https://doi.org/10.1080/15538605.2016.1233840

29. Kessler, R.C., Andrews, G., Colpe, L.J., et al.: Short screening scales to monitor population prevalences and trends in non-specific psychological distress. Psychol. Med. 32(6), 959-976 (2002). https:// doi.org/10.1017/s0033291702006074

30. Konishi, C., Hymel, S., Zumbo, B.D., et al.: Investigating the comparability of a self-report measure of childhood bullying across countries. Can. J. Sch. Psycho. 24(1), 82-93 (2009). https://doi. org/10.1177/0829573509331614

31. Hamby, S.L., Finkelhor, D.: The victimization of children: recommendations for assessment and instrument development. J. Am. Acad. Child Adolesc. Psychiatry 39(7), 829-840 (2000). https://doi. org/10.1097/00004583-200007000-00011

32. Kert, A.S., Codding, R.S., Tryon, G.S., Shiyko, M.: Impact of the word "bully" on the reported rate of bullying behavior. Psychol. Sch. 47(2), 193-204 (2009). https://doi.org/10.1002/pits.20464

33. Lund, E.M., Ross, S.W.: Peer victimization in students who are deaf and hard of hearing: exploring educational placement. J. Am. Deaf. Rehabi. Assoc. 50(2), 20-43 (2016b)

34. Cohen, J.: A power primer. Psychol. Bull. 112(1), 155-159 (1992). https://doi. org/10.1037/0033-2909.112.1.155

35. George, D., Mallery, P.: SPSS for Windows Step by Step: A Simple Guide and Reference. Allyn and Bacon, Boston (2003)

36. Fisher B, Cullen F, Turner M.: The sexual victimization of college women. U.S. Department of Justice. https://www.ncjrs.gov/pdffiles1/nij/182369.pdf (2000)

37. Blake, J.J., Kim, E.S., Lund, E.M., Zhou, Q., Kwok, O.-M., Benz, M.R.: Predictors of bully victimization in students with disabilities. J. Disabil. Policy Stud. 26(4), 199-208 (2016). https://doi. org/10.1177/1044207314539012

38. Forber-Pratt, A.J., Mueller, C.O., Andrews, E.E.: Disability identity and allyship in rehabilitation psychology: sit, stand, sign, and show up. Rehabil. Psychol. 64(2), 119-129 (2019). https://doi. org/10.1037/rep0000256

39. Oertle, K.M., Trach, J.S.: Interagency collaboration: the importance of rehabilitation professionals' involvement in transition. J. Rehabil. 73, 36-44 (2007)

40. Lewis WS, Schuster, SK, Sokolow BA.: Suicidal Students, BITs, and the Direct Threat Standard. National Council on Higher Education Risk Management. https://nabita.org/documents/2012N CHERMWHITEPAPERTHEDIRECTTHREATSTANDARDFINAL.pdf (2012)

Publisher's Note Springer Nature remains neutral with regard to jurisdictional claims in published maps and institutional affiliations. 